\title{
Call for Submissions: Special Issue, Cultural and Pedagogical Inquiry (CPI) Summer 2020
}

\author{
"I know why the caged bird sings"
}

Inspired by Maya Angelou's (1983) well known poem which compares and contrasts the characteristics of the free bird and the caged bird, this CPI Special Issue, explores minority resistance, resilience, and defiance. Angelou's poem describes the caged bird with clipped wings and tied feet. The metaphor of being caged can be expanded to apply to humans, specifically, to members of minoritized and racialized groups who encounter systemic restrictions and manmade forms of oppression. Such forms of oppression and domination include: structural racism and discrimination, micro-aggressions, alienation, isolation, loneliness, and exile.

In marked contrast, Angelou's poem states that the free bird swoops and soars, as it claims the sky. In speaking truth to power (Said) and in keeping with the spirit of Angelou's poem, the CPI issue for summer 2020, addresses collective and individual strategies of resistance, survival and growth, usually, despite overwhelming odds. The issue analyzes the strategies which are adopted by immigrants from the south, and visible minority women, men and youth in the diaspora.

We invite submissions (articles, poetry, artwork and music) which analyze ways in which minoritized groups demonstrate strength, creativity, resilience, agency, and indomitable spirits.

Potential authors and artists interested in contributing to this international, CPI Special Issue, please submit a proposal in either a single Word or PDF file to any the following Guest Editors:

Cecille DePass: depassc@ezpost.com

Enid Lee: enidlee@aol.com

Sonia Aujla-Bhullar: skaujla@gmail.com

Alleson Mason: mason@ualberta.ca

Deadline for submission: July 30, 2019

Your proposal should include:

- Title (up to 150 characters);

- Abstract (100-150 words);

- Description of the paper or artwork (400 words maximum). 